\title{
Computer ethics statement
}

\section{Prepared by the library staff at Southern Methodist University}

\section{Defining acceptable uses of computer networks}

t the request of a number of library employees at Southern Methodist University (SMU), a draft statement on computer ethics to guide and direct library personnel in appropriate and acceptable use of personal computers connected to the campus networks and mainframe (with interconnectivity to the Internet and other local, regional, national, and international networks) was developed.

The major focus was to encourage library personnel to learn and be active participants in online networking and access to electronic information resources, for position-related responsibilities, for professional networking, and even for personal interest. A second focus was to ensure that professional responsibility was employed in such interactive telecommunications through the Internet (including electronic mail, activity in special interest group forums, and other similar network communication).

The draft was circulated to all library personnel for suggestions and revisions. The results were positive and constructive and the final copy was approved by the Executive Committee of Central University Libraries (key administrators) and the Council of Library Directors [Central University Libraries, Bridwell (theology) Library, and Underwood Law Library]. The statement of computer ethics has led to effective, acceptable, and appropriate interactive online communications on the part of all library personnel. It was at their request that this document was submitted to CERL News for publication as a possible model for other libraries, and for further suggestions in development of the "Computer Ethics Statement."

\section{Etiquette}

As a common courtesy, always identify oneself beyond the e-mail address header, with a name and location at the end of the message.

Recognize that the nature of the lists is professional and academic, so keep discussion on appropriate topics and avoid flaming, or overreacting.

Recognize that the lists and messages reach a broad area, often nationally and internationally, so maintain accuracy and relevance in your computer use and communication. You are not representing SMU officially, but your actions and words reflect on the university.

Avoid capitalization of words or lines, as it is hard on the eyes and gives the appearance of "shouting" in print.

\section{Ethics}

Always use a computer in ways that show consideration and respect for your fellow humans. This means:

- Focus on using electronic communication to make work easier and of a higher quality, rather than to harm people.

- Pay for copying or using proprietary software. Neglecting to do so is stealing as data, programming, and intellectual output are commodities similar to merchandise, and the author or owner deserves compensation.

- Obtain permission and/or give proper compensation for the use of other people's computer resources.

- Respect other people's privacy and refrain from accessing their computer files without permission.

- Think about the social consequences of the program you are writing or the system you are designing.

(The above guidelines have been adapted from the Ten Commandments of Computer Etbics, a voluntary code of conduct for users of 
computer technology by the Computer Ethics Institute in Washington.)

SMU Libraries and the university will regard misuse of computing as serious offenses. Firsttime abusers will be warned. Any subsequent abuse may mean loss of e-mail access and further disciplinary action, if necessary.

SMU Libraries encourages department/division heads to assign responsibility within each department of a library to monitor special interest group forums, electronic journals, and other similar listserv information and to forward information to others as deemed appropriate to position duties and responsibilities.

SMU library staff are encouraged to monitor/respond to personal interest forums prior to or following work hours, during breaks, or lunch hours, or otherwise outside the official work day.

SMU library staff are encouraged not to reveal passwords over the telephone or in person to others without explicit knowledge and approval of how the other person may use these passwords. This is to discourage misuse of passwords to gain access to confidential information or to change or tamper with data files.

The Bradfield Computing Center staff should only be asked to print work-related informa- tion, not information from the "personal" lists. Such personal-interest information should be printed from printers attached to terminals for screen dump printing and during nonwork hours.

\section{References}

There are many user guidelines and electronic mail etiquette ("netiquette") documents available. Citations to a few of these are:

Feinberg, Andrew. "Netiquette." Lotus 6, no. 9 (1990): 66-69.

FTP.SURA.NET Filename is: NETIQUETTE. TXT.

Goode, Joanne, and Maggie Johnson. "Putting Out the Flames: The Etiquette and Law of E-Mail." ONLINE 61 (November 1991): 61-65.

Public Law 99-508. Approved October 21, 1986. [5, sec 2703]

Shapiro, Norman Z., and Robert H. Anderson. Toward an Ethics and Etiquette for Electronic Mail. Santa Monica, Calif.: Rand Corporation, 1985. Available as Rand Document R-3283NSF/RC and ERIC Document ED 169003.

Turner, Judith. "E-Mail Technology Has Boomed, but Manners of Its Uses Fall Short of Perfection." Chronicle of Higher Education 34, no. 31 (April 13, 1988): A1, A16.

\section{(...With Washington Alert, the premier tracking (1) service of Congress and regulatory agencies G1 Gi coseated by Congressional Quarterly. \\ With 23 fully searchable databases, it offers a remarkably detailed picture of Congress. \\ Washington Alert offers a comprehensive depository of information on the federal government along with full text of many CQ Publications-the ideal one-stop reference source for librarians and patrons looking for current and retrospective legislative information. \\ And it's now accessible via the Internet. \\ For more information contact Waldo Tibbetts at $1(800) 432-2250$ ext. 350 (in D.C., contact 887-6350), or internet WTIBBETTS@CQALERT.COM, or write to Congressional Quarterly, 1414 22nd St., N.W., Washington, D.C. 20037.}

